\title{
Desigualdad en el acceso educativo en México: Un estudio con sujetos egresados de un bachillerato tecnológico de alto desempeño
}

\author{
Inequalities in Educational Access in Mexico: \\ A Study with Graduates Students of a High Performance Technical High School

 \\ Fernando Pérez-Santiago' \\ Instituto Tecnológico de Úrsulo Galván-Tecnología \\ Úrsulo Galván, México \\ correo: santiago_fps91@hotmail.com \\ orcid: http://orcid.org/0000-0002-4437-2290 \\ Manuel Villarruel-Fuentes ${ }^{2}$ \\ Instituto Tecnológico de Úrsulo Galván-Tecnología \\ Úrsulo Galván, México \\ correo: dr.villarruel.fuentes@gmail.com \\ orcid: http://orcid.org/0000-0002-1174-0528
}

Recibido 10 de noviembre de 2015 • Corregido 17 de julio de 2016 • Aceptado 16 de agosto de 2016

\begin{abstract}
1 Investigador adjunto al Grupo de Investigación Socioeducativa del Instituto Tecnológico de Úrsulo Galván. Colaborador en el cuerpo académico "Cultura Empresarial y Desarrollo Social Sustentable" dentro del proyecto denominado "Competencias científicas y modelos didácticos: La enseñanza de la ciencia en el nivel superior tecnológico", avalado y financiado por el Tecnológico Nacional de México. Es miembro de la Red Veracruzana de Investigación e Innovación Educativa para el Tecnológico Nacional de México.

${ }^{2}$ Es Investigador Nacional Nivel 1 (SNI). Miembro del Consejo Mexicano de Investigación Educativa. Miembro de la Red Virtual de Estudios de Ciencia, Tecnología, Sociedad e Innovación de la Organización de Estados Iberoamericanos. Es miembro de la Academia Veracruzana de Ciencias Agrícolas, Pecuarias, Forestales, Acuícolas y Pesqueras, donde es integrante de la Junta de Honor y Justicia. Líder del cuerpo académico "Cultura Empresarial y Desarrollo Social Sustentable". Evaluador nacional acreditado por el CONACYT y miembro del Banco Iberoamericano de Evaluadores (España, Colombia, Argentina, Uruguay y México). Como líder del grupo de investigación dentro del tecnológico de Úrsulo Galván desarrolla actualmente el proyecto denominado "Competencias científicas y modelos didácticos: La enseñanza de la ciencia en el nivel superior tecnológico", avalado y financiado por el Tecnológico Nacional de México. Es, además, presidente de la Red Veracruzana de Investigación e Innovación Educativa para el Tecnológico Nacional de México.
\end{abstract}


doi: http://dx.doi.org/10.15359/ree.20-3.21

URL: http://www.una.ac.cr/educare

CORREO: educare@una.cr

Resumen. El acceso al sistema educativo de nivel superior en México se ha caracterizado por desigualdades educativas, explicadas por corrientes sociales y reproduccionistas. El fenómeno se presenta en sujetos egresados de bachilleratos con distintos orígenes -sociales, culturales, económicos, institucionales y académicos- que provocan un proceso de transición alejado de la igualdad de oportunidades. Por ende, las diferencias existentes por la diversidad cultural no generan el acceso equitativo a las instituciones de educación superior (IES). El objetivo consistió en identificar los factores sociales, culturales y académicos que inciden en el ingreso o abandono de la formación académica de estudiantes con expectativas de acceso hacia la educación superior. La investigación se fundamenta a partir de los resultados obtenidos en 40 sujetos técnicos graduados de un bachillerato tecnológico de alto desempeño académico en México, que se perfilaban para ingresar al nivel superior. El diseño de la investigación fue exploratorio-descriptivo con enfoque cualitativo, se aplicaron dos cuestionarios con ítems de opción múltiple, cuyos resultados fueron analizados interpretativamente. El muestreo fue no probabilístico, con la técnica "bola de nieve" y por "conveniencia". Los resultados mostraron que el nivel de escolaridad de los padres y madres, las relaciones sociales y la trayectoria académica de la persona egresada actuaron como determinantes en el ingreso al nivel superior, por lo que se concluye que el origen estudiantil genera desigualdad en el logro educativo.

Palabras claves. Educación superior, transición educativa, trayectoria académica.

Abstract. Access to the higher education system in Mexico has been characterized by educational inequalities explained by social and reproductionist currents. The phenomenon occurs in graduate students with a high school diploma and coming from different contexts (social, cultural, economic, institutional and academic ones) that create a process of transition far away from equal opportunities. Therefore, the differences due to cultural diversity do not generate equitable access to higher education institutions. The aim of this study was to identify the social, cultural and academic factors affecting the access to or the abandonment of the academic education of students with expectations of entering the higher education system. The research was based on the results obtained from forty technicians who studied at a vocational high school with high academic performance in Mexico, and were supposed to enter the higher level. It was an exploratory descriptive investigation with qualitative approach, using two multiple-choice item questionnaires whose results were analyzed interpretively. The sampling was non-probability, with the technique of "snowball" and "convenience". The results showed that the level of parents' schooling, social relations, and academic career of graduates were decisive to enter the higher education; so it can be concluded that the students' origin generate inequality in educational achievement.

Keywords. Higher education, educational transition, academic background.

\section{Introducción}

A la entrada de siglo XXI las desigualdades educativas en México han proliferado, lo que generó la decantación de la población hacia la formación académica o el abandono educativo. El fenómeno se ha exacerbado durante la última década, debido a que jóvenes que egresan del nivel medio superior no logran la transición educativa a instituciones de educación superior (IES), nivel en el que el sujeto egresado recibe la formación profesional para el desempeño laboral. Al respecto, se establece que "la desigualdad de oportunidades para ingresar al nivel superior 
ha sido un problema que enfrentan diversos países desde hace décadas; al paso del tiempo, lejos de encontrarse respuestas satisfactorias a este problema, se ha ido agudizando" (Guzmán \& Serrano, 2011, p. 33).

En busca de lograr un nivel de igualdad en la educación, es necesario considerar el artículo 26 por la Declaración Universal de los Derechos Humanos (1948), en el que se consigna el compromiso de lograr un acceso equitativo al nivel superior:

Toda persona tiene derecho a la educación. La educación debe ser gratuita, al menos en lo concerniente a la instrucción elemental y fundamental. La instrucción elemental será obligatoria. La instrucción técnica y profesional habrá de ser generalizada; el acceso a los estudios superiores será igual para todos, en función de los méritos respectivos. (Artículo 26. Párr. 1)

Lo anterior permite concebir que todo individuo -independientemente de los orígenes sociales, culturales, económicos, académicos e institucionales- debe tener igualdad de oportunidades para acceder a la educación, en especial, al nivel superior; tendencia negativa evidenciada en México, por lo que es preciso que el país ofrezca las mismas oportunidades de acceso educativo, además de educación de calidad a los sectores desfavorecidos. Aunado a ello, el mayor problema está situado en el proceso de transición hacia el ingreso al nivel superior; por si eso fuera poco, se le añaden los problemas de reprobación, rezago educativo y baja eficiencia terminal que se suscita dentro de las IES (Guzmán \& Serrano, 2011).

Se destaca que el ingreso a las IES en los últimos años se perfila como vasto; a nivel nacional el ciclo escolar 2013-2014 incrementó un 3.61\% de estudiantes que accedieron al nivel superior en relación con el ciclo anterior (Secretaría de Educación Pública, SEP, 2014b). Durante el periodo señalado la matrícula se sostuvo con 3.600 .000 estudiantes que cursaban estudios de licenciatura -sistema escolarizado y no escolarizado- con una cobertura de $33.1 \%$ de la población (Gobierno de los Estados Unidos Mexicanos, 2014). Los datos no aseguran un acceso equitativo en la educación, debido a que se desconoce el sector beneficiado, y se rechaza el supuesto en que, a mayor cobertura, mayor acceso equitativo en la educación. Por lo que se sostiene que en el país impera y se expande la desigualdad para acceder a la educación, con impacto negativo en la población. La desigualdad educativa se presenta en diversos escenarios demográficos, sustentado por lo que señala Ortiz (2014): “El sistema educativo, a pesar de los cambios institucionales, curriculares y pedagógicos, sostuvo -y legitimó- la persistencia de las desigualdades educativas entre las categorías sociales, constatándose que el acceso educativo no es igual a las condiciones sociales del acceso" (p. 46). Esto es, las oportunidades de ingreso al nivel superior no garantizan equidad, ya que existen sectores sociales que no están en condiciones de gestionar dicho ingreso, generalmente por falta de recursos. 
doi: http://dx.doi.org/10.15359/ree.20-3.21

URL: http://www.una.ac.cr/educare

CORREO: educare@una.cr

Aunado a lo anterior, se debe incluir que "las desigualdades educativas observadas en la distribución social de conocimientos escolares básicos y en el efecto de las escuelas sobre aquéllas, estarían fijadas a modo de contexto o entorno por la estructura del sistema educativo nacional" (Fernández, 2002, p. 502). Al respecto, se menciona que el sistema educativo en México no parece ser la excepción, debido a la exclusión que se genera para ingresar al nivel superior por factores como la competencia y demanda, sujeta a las oportunidades de ingreso.

En atención al fenómeno problemático, se cuestiona la igualdad de oportunidades para el acceso a la educación superior, en el entendido de que las diferentes estrategias implementadas desde las políticas educativas -incremento de becas, aumento de matrícula, disminución de cuotas, por mencionaralgunas-no han sido suficientes. Respecto al incremento dela matrícula, se hace evidente que quienes logran ocupar los lugares abiertos son aquellos sectores que poseen los recursos -sociales, culturales y económicos- para continuar su preparación académica, por lo que la distribución para el ingreso al nivel superior está sujeta a múltiples factores.

Desde estas premisas, la educación en el nivel superior se caracteriza por la masificación de las IES con problemas de calidad en la formación de estudiantes. Los datos no aseguran el acceso educativo con igualdad de oportunidades. Sobre ello, se indica que "si la cobertura de la educación superior crece, esto beneficiará a los sectores sociales más desfavorecidos, que han sido históricamente excluidos" (Solís, 2014, Párr. 2); sin embargo, el problema se presenta al persistir una notoria desigualdad en el acceso a la educación y calidad en el sistema educativo. El problema se agudiza cuando el sujeto egresado no logra la transición entre nivel medio y superior, asociado con carencias sociales, económicas, culturales, entre otras. La realidad se evidencia con lo señalado por Latapí (2002):

Somos uno de los países de mayores desigualdades económicas del mundo y tenemos, además, un sistema escolar profundamente inequitativo; las oportunidades -de acceso, permanencia, extensión de la escolaridad y, sobre todo, aprendizaje efectivo y calidad- se distribuyen muy desigualmente entre ricos y pobres. La desigualdad ha marcado nuestra educación desde siempre y, aunque cada gobierno promete disminuirla y algunos han hecho esfuerzos serios y consistentes, los sexenios, también el último, terminan con saldos insatisfactorios. (p. 665)

Estos postulados se complementan con lo expresado por Blanco (2009), quien argumenta que "al igual que la mayor parte de los países de la región, en México existe una acentuada desigualdad educativa, fenómeno del cual la diferencia de aprendizaje es una de las manifestaciones más notorias" (p. 1020). Lo preocupante estriba en la diversidad de personas egresadas que traen consigo deficiencias que actúan como determinantes en el logro educativo evidenciado con el ingreso o abandono de las IES. Sumado a ello, se publican cifras sobre el crecimiento de la matrícula en educación superior, debido a la expansión de instituciones, 
las cuales hacen pensar ingenuamente que se está alcanzando un nivel de igualdad de oportunidades; peor aún, que se están gestando instituciones de calidad. Sobre esta base, se cuestionan las oportunidades que reciben las personas de sectores desfavorecidos, así como el tipo de formación académica que algunas logran adquirir, resultado que conlleva a reflexionar sobre el tipo de población a la cual se le otorga educación.

Con estos referentes, Muñoz-Izquierdo (1996) reveló que las desigualdades educativas presentadas:

Se originan en el hecho de que la educación que se ofrece a los estratos sociales de menores recursos está pauperizada, no es administrada de acuerdo con los intereses de esos sectores y, por ende, refuerza las desigualdades sociales preexistentes. (pp.129-130)

Sobre este talante, se señala que las desigualdades educativas se han condicionado por el aumento de la matrícula en condiciones donde la oferta en el acceso a estudios profesionales ha proliferado en medio de la inequidad (Latapí, 2002). El problema se agrava en jóvenes que no son culpables de sus orígenes, al traer consigo problemas expuestos por las deficiencias del sistema educativo. Por lo que se propugna un contexto con igualdad de oportunidades, en el entendido que se desea alcanzar:

Un nivel superior de igualdad se encuentra cuando, una vez garantizada la igualdad en el acceso, se proporciona un programa educativo similar a todos los alumnos y se evita, en consecuencia, que los que proceden de clases sociales populares estén mayoritariamente representados en los programas menos valorados social y académicamente: aulas especiales, programas de educación compensatoria, programas de garantía social. (Marchesi, 2000, p. 136)

El reto estriba en "ampliar y diversificar las oportunidades de acceso a la educación superior y acercar la oferta educativa a los grupos sociales en situación de desventaja, así como a la población indígena del país" (SEP, 2001, p. 189). Sobre ello, es necesario brindar educación de calidad a todos los sectores, independientemente de sus orígenes sociales y, en caso de otorgar el acceso a las IES a la población desfavorecida, tendrá que sujetarse a las condiciones necesarias -infraestructura, programa de estudio, docentes con aptitud, entre otros- para un aprendizaje adecuado.

Sobre el fenómeno mencionado se indica que se han realizado diversas investigaciones derivadas de la desigualdad en el acceso a la educación (Blanco, 2011, 2014; Guzmán \& Serrano, 2011; Latapí, 2002; Muñoz-Izquierdo, 1996; Sousa, Lopes \& Ferreira, 2013; Villa, 2014; Zagal-Carreño et al., 2006), por lo que se justifica la realización de estudios centrados en el proceso de transición educativa, del nivel medio superior al superior, en jóvenes provenientes de una institución de 
doi: http://dx.doi.org/10.15359/ree.20-3.21

URL: http://www.una.ac.cr/educare

CORREO: educare@una.cr

"alto desempeño", la cual se afirma provee una formación académica y humana de calidad. Dicho fenómeno se hace evidente al finalizar el ciclo escolar, en el que estudiantes ven truncadas sus oportunidades para ingresar a una IES, en comparación con una élite que logra ingresar al nivel superior, por el supuesto de que tienen mejor preparación académica, sin considerar los orígenes culturales, sociales, económicos, académicos e institucionales que les caracteriza.

Con base en lo anterior, se muestran los resultados obtenidos en un grupo de sujetos egresados de un bachillerato tecnológico, cuyas expectativas de ingreso al nivel superior se vieron impedidas por factores diversos, los cuales se describen y analizan a continuación.

\section{Materiales y métodos}

El estudio se realizó con sujetos egresados de la generación 2011-2014 del Centro de Bachillerato Tecnológico Agropecuario N. 17 (C.B.T.a N. ${ }^{\circ}$ 17), localizado en el estado de Veracruz, México. El C.B.T.a N. 17 es una institución de alto desempeño académico, certificada en el proceso de formación, habilidades y competencias ISO 9001-2000, además de tener el Reconocimiento a la Calidad SEP 2006 (C.B.T.a N. ${ }^{\circ}$ 17, 2016). Ofrece actualmente las carreras de Técnico Agropecuario, Explotación Ganadera, y Administración y Contabilidad Rural; esta última, la segunda de mayor antigüedad y nivel de matrícula, en la que los sujetos egresados obtuvieron los mejores resultados en la Prueba Enlace 2014, en la categoría de comunicación y matemáticas (SEP, 2014a).

El abordaje metodológico fue cualitativo, el cual "produce hallazgos a los que no se llega a través de procesos estadísticos. Sin embargo, acoger este postulado no niega la posibilidad de cuantificar algunos datos cuando sea necesario" (Rosero, 2012, p. 43), sobre todo en los resultados basados en el análisis interpretativo. Se catalogó como un estudio exploratoriodescriptivo. La población se conformó por 79 sujetos egresados de la carrera de Administración y Contabilidad Rural, agrupados en dos estratos: 54 que habían ingresado al nivel superior y 25 que no continuaron su formación académica. El muestreo fue no probabilístico, con la aplicación de la técnica bola de nieve y por conveniencia, sustentada en que "no hay reglas para decidir el tamaño de la muestra y, si hubiera que enunciar alguna, esta sería: 'todo depende'. Depende del propósito de estudio, de lo que resulta útil para lograrlo, de lo que está en juego, de lo que lo hace verosímil y, en última instancia, incluso de lo que es posible" (Martínez-Salgado, 2012, p. 616). La validez en este tipo de muestreo se logra por medio de la triangulación, lo que implica "contar con la opinión de uno o más investigadores en la interpretación de tales resultados" (Álvarez-Gayou, 2003, p. 31).

La muestra seleccionada fue de 40 sujetos egresados (20 que ingresaron al nivel superior y 20 que no continuaron su formación académica). La técnica de recolección se caracterizó por el diseño de "cuestionarios" para la obtención de información sobre datos generales, así como el estudio de 
tres categorías de análisis: capital cultural, capital social y trayectoria académica. La evidencia se analizó mediante una estadística descriptiva bajo noción nomotética. Se empleó el programa Excel de Microsoft y el software SPSS (Statistical Package for the Social Sciences), versión 19.0.

\section{Resultados y discusión}

\section{Datos generales}

Los resultados confirmaron, tal como señala Colorado (2009), que "Ios jóvenes que logran ingresar a las instituciones de educación superior, como lo muestran distintos estudios, no son un grupo homogéneo" (p. 1), al caracterizarse el contexto por la diversidad cultural, lo que llevó a identificar el perfil de los sujetos egresados según el género y localidad en la que habitaron durante los estudios del nivel medio superior.

Respecto al género, el $75 \%$ de los que "ingresaron" al nivel superior fueron mujeres y $25 \%$ hombres. El ingreso hace evidente que las mujeres hicieron valer el "... derecho a las mismas oportunidades que sus colegas masculinos en lo referente al acceso a la enseñanza [de la educación] superiory a las carreras profesionales"(Rodríguez, 1999, p. 127). Sin embargo, al margen de ello, habrá que considerar lo señalado por Guzmán y Serrano (2011), quienes, en referencia a lo académico, señalan "que hay estilos diferenciados en relación con el conocimiento y con las metas educativas; por lo regular, las mujeres son mejores estudiantes que los hombres, en términos que tienen un mejor desempeño, rendimiento y resultados educativos" (p. 41). Pero más allá de una posible superioridad académica mostrada por las mujeres, existe una tendencia que señala mayores facilidades para su ingreso al nivel superior, o bien, que los factores académicos -estilo de aprendizaje y habilidades- que determinan el ingreso operan a favor de este género.

En el grupo que "no ingresó" al nivel superior, se evidencia que el 55\% son hombres y el $45 \%$ mujeres. Los resultados permiten afirmar que probablemente en el género femenino interactúan factores a favor para continuar su formación académica hacia estudios de nivel profesional, los cuales exigen disciplina, compromiso, responsabilidad, madurez emocional, apoyo familiar y económico, e interés por la superación. Lo anterior señala que posiblemente el género del egresado es un factor que actúa como determinante para ingresar al nivel superior, lo que hace pensar que el ambiente social y cultural en el que interactúan -según el género- está expuesto a conductas que distan sobre la superación profesional (Guzmán \& Serrano, 2011).

De la misma manera se caracterizó el tipo de localidad en la que habitó el egresado, al considerar que "la educación en el medio rural dispone de menos recursos didácticos y humanos, lo que afecta la calidad de la educación, y más preocupante aún es que la mayor 
doi: http://dx.doi.org/10.15359/ree.20-3.21

URL: http://www.una.ac.cr/educare

CORREO: educare@una.cr

parte de la población rural se encuentre en condiciones de pobreza y es totalmente injusto que hagan un gasto mayor en la educación de sus hijos" (Zagal-Carreño et al., 2006, p. 264). Sobre esta variable es posible afirmar que la mayoría de jóvenes que provienen de localidades urbanas poseen mayores recursos económicos, acceso a instituciones educativas de calidad y oportunidades para establecer relaciones sociales con personas que cursaron estudios a nivel superior. En contraparte, es posible que la mayoría de las personas que habitan en localidades rurales se vean expuestas a la pobreza, la cual, al ser recurrente, erige desigualdades entre los grupos sociales que pueden incidir en la formación académica.

Respecto al grupo que ingresó a las IES, se identificó que el 55\% provenía de zonas urbanas y el $45 \%$ de rurales. De los grupos de jóvenes que no ingresaron el $65 \%$ eran residentes de zonas rurales y el 35\% de urbanas (ver Tabla 1). Se destaca que la formación académica de jóvenes de origen rural, posiblemente, es un factor determinante en su desempeño académico, al señalar que "en el sector rural las escuelas se ubican lejos de donde se vive, a veces no cubren todo el ciclo primario y en las periferias urbanas las condiciones de estudio son inadecuadas" (García, Bracho, Ibarrola, Rodríguez \& Schmelkes, 1998, p. 318). Los resultados sobre sujetos egresados indican que probablemente el tipo de localidad -rural o urbana- en la que habitó fue un factor determinante para ingresar al nivel superior, al considerar que las localidades de origen promueven la desigualdad en el ingreso al nivel superior y que influyen en el éxito o fracaso académico a partir de factores sociales, económicos y culturales. Ello hace evidente que "en la zona rural confluyen otros factores de vulnerabilidad, como la pobreza y la mayor concentración de poblaciones originarias... La escasez de oportunidades y de servicios de todo tipo en la zona rural" (Blanco \& Cusato, s. f., Párr. 3), los cuales afectan en el proceso de transición educativa. En este sentido, es necesario establecer que el habitar en zonas rurales tiene un efecto que no favorece el ingreso al nivel superior.

Tabla 1

Género y tipo de localidad de los sujetos egresados del C.B.T. N N. 17 que ingresaron y no a las IES en Veracruz, México

\begin{tabular}{cccc}
\hline \multicolumn{2}{c}{ Dimensiones } & Egresados que ingresaron a IES & Egresados que no ingresaron a IES \\
\hline \multirow{2}{*}{ Género } & Masculino & $25 \%$ & $55 \%$ \\
& Femenino & $75 \%$ & $45 \%$ \\
\hline \multirow{2}{*}{ Localidad } & Rural & $45 \%$ & $65 \%$ \\
& Urbana & $55 \%$ & $35 \%$ \\
\hline
\end{tabular}

Nota: Elaboración propia. 
A partir de los resultados, se hace necesario ofrecer educación a la población que carece de recursos -sociales, económicos y culturales- para que continúen su formación académica. Es menester atender la diversidad cultural que está expuesta a la persistente desigualdad, y replantear una educación de calidad, en el entendido de que el sistema, a pesar del aumento de la matrícula escolar, no atiende a los sectores más desfavorecidos, excluyéndolos del sistema educativo. Como complemento de la evidencia se manifiesta que "los centros donde asisten los alumnos más pobres no solamente son pobres en recursos, sino en expectativas: los maestros se han resignado a que sus alumnos aprendan poco" (Blanco, 2009, p.1022), por lo que es posible que el contexto escolar en el que se inicia la formación académica sea un elemento clave para obtener resultados favorables en los siguientes niveles educativos, al traer consigo deficiencias académicas, principalmente en jóvenes que provienen de localidades rurales.

\section{Categoría: capital cultural}

Un análisis sobre desigualdades educativas necesariamente pasa por la dimensión denominada capital cultural (Bourdieu, 2001). Sobre esta base y de acuerdo con Blanco (2014), se establece que"el capital cultural del hogar ejerce una influencia persistente en el logro escolar y que esta influencia está separada de características asociadas pero teóricamente secundarias" (p. 260). En lo que se refiere a las características de familiares, se indagó específicamente el nivel de escolaridad de los padres y madres, lo cual posiblemente generó pautas en los hijos e hijas sobre el ingreso o no al nivel superior.

Sobre ello, Guzmán y Serrano (2011) señalan que la familia con "altos niveles de escolaridad cuenta con recursos para apoyar a los hijos materialmente, para orientarlos y para apoyarlos en las tareas educativas" (p. 46). A partir de lo anterior, se identificó el porcentaje que cursó estudios a nivel de posgrado y licenciatura, en virtud de que esto puede actuar como factor determinante en el logro educativo. Los sujetos egresados que "continuaron su formación académica" provienen de padres y madres sin estudios de posgrado (0\%). En el nivel de licenciatura se identificó que el $22.5 \%$ de progenitores ingresó a una carrera profesional, sin embargo, únicamente el $5 \%$ concluyó dichos estudios, y el 17.5\% no concluyó; es posible que los problemas para concluir satisfactoriamente un nivel académico sean trasmitidos hacia los miembros del hogar, al considerar que "la experiencia escolar de los padres es elemento de suma importancia en el apoyo a la trayectoria escolar de los jóvenes" (Zagal-Carreño et al., 2006, p. 273). Aunado a ello, el problema se yergue en los padres y madres de jóvenes que continuaron su formación académica, quienes no cursaron estudios de posgrado ni a nivel superior, dejando entrever un bajo nivel de escolaridad y los siguientes supuestos: 1) que los padres y madres no posean las habilidades cognitivas para apoyar a los hijos e hijas en sus actividades académicas, 2) y que el origen académico sea determinante en los hijos e hijas para continuar sus estudios académicos. 
doi: http://dx.doi.org/10.15359/ree.20-3.21

URL: http://www.una.ac.cr/educare

CORREO: educare@una.cr

Respecto a los estudios del nivel medio superior de sus progenitores, el grupo que pudo ingresar al nivel superior provino de padres y madres que en el $35 \%$ ingresó al bachillerato, pero que en un $30 \%$ desertó durante los cursos y únicamente el $5 \%$ egresó. Mientras tanto, los padres de jóvenes que no continuaron su formación académica hacen evidente que el $30 \%$ ingresó al nivel medio superior y en su totalidad egresó de forma satisfactoria. Aunque se denota que en el segundo grupo no existió deserción por parte de los padres y madres, se asume que posiblemente fueron otros factores los que generaron el ingreso o no al nivel superior. Además, el descender de personas que ingresaron, pero no concluyeron sus estudios académicos, posiblemente se constituya como factor que genera en los hijos e hijas aspiraciones encaminadas hacia un logro educativo superior, lo cual esté sujeto a la cultura académica creada en el hogar.

Sobre los estudios de secundaria se hizo evidente la deserción de los padres y madres del grupo de sujetos egresados que continuó su formación profesional, al identificar que el $25 \%$ ingresó, pero en su mayoría desertó (17.5\%) y solo el $7.5 \%$ concluyó. Ello comprometió el conjunto de valores que trasmitieron a los hijos e hijas; sin embargo, al parecer no fue determinante en su elección para ingresar al nivel superior. Estos resultados posiblemente generen en el alumnado aspiraciones para concluir de forma satisfactoria sus estudios, a pesar de su origen cultural, dejando fuera los factores familiares, sociales y económicos que pueden presentarse.

Al indagar sobre el nivel de estudios básicos que poseían los padres y madres -primaria-, se hace evidente en el grupo que no ingresó al nivel superior la procedencia de familiares en el que un $35 \%$ inició la formación básica, pero el $17.5 \%$ desertó en los estudios y el $17.5 \%$ concluyó. El bajo nivel de escolaridad de los padres y madres posiblemente sea un factor determinante para continuar su formación académica, al señalar que "el nivel académico y económico de los padres es un apoyo sólido para que el hijo continúe con los estudios" (Zagal-Carreño et al., 2006, p. 73). El problema se agrava cuando el $20 \%$ no tuvo estudios académicos, lo que probablemente sea uno de los factores determinantes en el nivel de escolaridad de los hijos e hijas.

En busca de mayores referencias sobre el nivel académico de los "padres" del grupo que ingresó al nivel superior, se evidencia que el $17.5 \%$ se incorporó a la primaria, y el $15 \%$ no concluyó, con un $2.5 \%$ que egresó (ver tabla 2). Aunque se presentó un bajo nivel de escolaridad en el grupo no parece ser determinante en el rumbo académico de los sujetos egresados. Además, se señala que todos los padres y madres poseyeron estudios, independientemente si egresaron o no. Los resultados actúan como factor determinante, debido a que el origen no es destino en este grupo de sujetos egresados. 
Tabla 2

Nivel de escolaridad del padre y madre de sujetos egresados del C.B.T.a N. 17 que ingresaron y no a IES en Veracruz, México

\begin{tabular}{|c|c|c|c|c|}
\hline \multirow{2}{*}{$\begin{array}{c}\text { Dimensiones } \\
\text { Escolaridad de los padres }\end{array}$} & \multicolumn{2}{|c|}{ Sujetos egresados que ingresaron a IES } & \multicolumn{2}{|c|}{ Sujetos egresados que no ingresaron a IES } \\
\hline & Concluyeron & No concluyeron & Concluyeron & No concluyeron \\
\hline Primaria & $2.5 \%$ & $15.0 \%$ & $17.5 \%$ & $17.5 \%$ \\
\hline Secundaria & $7.5 \%$ & $17.5 \%$ & $15.0 \%$ & $0.0 \%$ \\
\hline Medio superior & $5.0 \%$ & $30.0 \%$ & $30.0 \%$ & $0.0 \%$ \\
\hline Superior & $5.0 \%$ & $17.5 \%$ & $0.0 \%$ & $0.0 \%$ \\
\hline Posgrado & $0.0 \%$ & $0.0 \%$ & $0.0 \%$ & $0.0 \%$ \\
\hline No estudiaron & \multicolumn{2}{|c|}{$0.0 \%$} & \multicolumn{2}{|c|}{$20.0 \%$} \\
\hline
\end{tabular}

Nota: Elaboración propia.

Los resultados, en concordancia con la teoría del capital cultural de Bourdieu (2001), indican que el grado de escolaridad de los padres y madres influye en la presencia de los sujetos egresados para continuar los estudios en el nivel superior. En este sentido, la familia trasmite un conjunto de aspiraciones, cultura y saberes sobre el nivel de estudios que se debe alcanzar, por lo que "el título académico es un certificado de competencia cultural que confiere a su portador un valor convencional duradero y legalmente garantizado" (p.146). Lo anterior se justifica a partir del beneficio que cada estudiante obtiene respecto al nivel académico de su padre y madre, debido a que es posible aprovechar los conocimientos y habilidades que posee la familia para formarse académicamente.

\section{Categoría: capital social}

De acuerdo con Coleman (citado por Ramírez y Hernández, 2012), las desigualdades sociales están sujetas al capital social, por lo que se indica que el acceso a las instituciones académicas depende, en gran medida, de los rasgos de la estructura social sobre factores relacionados con la familia, número de hermanos o hermanas y actividad de las personas con las que se relaciona.

Diversas investigaciones internacionales evidencian problemas en el desempeño académico del alumnado por la ausencia del padre o madre dentro del hogar, al generar diferencias en torno a su motivación y la valoración que le confiere a la educación, lo que puede llegar a disminuir los factores que condicionan el abandono (Amato, 1987; Astone \& 
doi: http://dx.doi.org/10.15359/ree.20-3.21

URL: http://www.una.ac.cr/educare

CORREO: educare@una.cr

McLanahan, 1991; Sandefur, Mclanahan \& Wojtkiewicz, 1992), ente otros. Desde este tenor, en la investigación se identificó la persona con quién habitó el sujeto egresado durante su formación académica, para lo que se consideró la madre, padre o ambos (Bourdieu, 2001), al entender que ello tiende a ser un factor determinante en el éxito o fracaso académico.

Respecto al alumnado que ingresó al nivel superior, el 75\% vivió con el padre y la madre, y el $25 \%$ solo con la madre. Sobre los sujetos egresados que no continuaron su formación académica se identificó que un $65 \%$ habitó con el padre y la madre, el $20 \%$ vivió con la madre y un $15 \%$ con el padre. Al respecto, se menciona que "los padres de familia deben conocer que toda perturbación en el hogar, falta de unión y buenas relaciones entre los miembros, repercuten de manera especial en la vida escolar de sus integrantes" (Zagal-Carreño et al., 2006, p. 275). Sobre esta base se identificó en los grupos de sujetos egresados que la mayoría tiene la presencia del padre y la madre dentro del hogar ( $75 \%$ y $65 \%$ respectivamente); sin embargo, es necesario destacar que posiblemente en los hogares catalogados como disfuncionales (35\%), de donde provienen jóvenes que no ingresaron a IES, la ausencia de alguna de estas figuras sea un obstáculo para alcanzar un mayor nivel de escolaridad, y su formación académica se vea afectada por problemas familiares, falta de apoyo motivacional y ausencia de atención. Aunque en ambos grupos el porcentaje es menor, se observa que de quienes ingresaron al nivel superior, el $25 \%$ proviene de hogares disfuncionales, lo cual no fue un factor que afectara negativamente su ingreso al nivel superior, interpretación no aplicable al segundo grupo.

Al profundizar sobre el capital social, Ramírez y Hernández (2012) señalan que "la mayor presencia de hijos diluía los recursos paternos y menguaba en forma proporcional su calidad de vida (medida... por el logro educativo del adulto)" (p. 7). Sobre la base de este aserto, fue necesario identificar el número de hermanos o hermanas del sujeto egresado. En el grupo que ingresó al nivel superior se señala que el 55\% tiene un hermano, el $10 \%$ cuenta con 2, el $15 \%$ tres, finalmente, el $20 \%$ no tiene hermanos. En el grupo se distingue que la menor presencia de hermanos pudo condicionar que los padres dispusieran de mayores recursos económicos, brindaran mejor apoyo académico y motivacional, además de generar la oportunidad de prestar atención sobre los problemas académicos. Se señala que la condición de sujeto egresado sin hermanos posiblemente genere beneficios positivos para ingresar al nivel superior, al poseer mayor cantidad de recursos económicos y sociales.

En relación con el número de hermanos del grupo que no ingresó al nivel superior, el 35\% tiene uno, el $50 \%$ cuenta con 2, el $5 \%$ tres, y finalmente el 10\% no tiene ningún hermano (ver tabla 3). Los datos señalan una mayor presencia de hijos dentro del hogar -en comparación con los que ingresaron a IES-, lo que posiblemente actúo como determinante para la superación profesional al interactuar factores como atención académica y gastos escolares. Los resultados obtenidos en el grupo de sujetos egresados que tuvieron un mayor número de hermanos posiblemente determine una menor atención de los padres y madres hacia los hijos e hijas, con lo que disminuiría el capital 
social, debido a que pueden generarse actividades simultáneas, en donde los padres o madres decidan elegir o rechazar, al mismo tiempo, a uno de ellos, y generar consecuencias negativas en la atención -académica y humana-, seguimiento y control paterno (Ramírez \& Hernández, 2012).

Tabla 3

Nivel de escolaridad del padre y madre del egresado del C.B.T.a N. ${ }^{\circ} 17$ que ingresaron y no a IES en Veracruz, México

\begin{tabular}{lccc}
\hline & & Sujetos egresados que ingresaron a IES & Sujetos egresados que no ingresaron a IES \\
\hline \multirow{3}{*}{ Familiar con el que habitó el sujeto egresado } & Padre & $0 \%$ & $20 \%$ \\
& Madre & $25 \%$ & $15 \%$ \\
& Ambos & $75 \%$ & $65 \%$ \\
\hline \multirow{2}{*}{ Número de hermanos/as } & No tiene & $20 \%$ & $10 \%$ \\
& 1 & $55 \%$ & $35 \%$ \\
& 2 & $10 \%$ & $50 \%$ \\
Actividad de las personas con las que se & 3 & $15 \%$ & $5 \%$ \\
relaciona en su comunidad & Estudia & $80 \%$ & $40 \%$ \\
& Trabaja & $20 \%$ & $50 \%$ \\
\hline
\end{tabular}

Nota: Elaboración propia.

En un abordaje más profundo, se identificó el tipo de relaciones que mantuvo el sujeto egresado, al considerar"que no sólo la familia podría influir en la deserción escolar, sino también la comunidad" (Ramírez \& Hernández, 2012, p. 5). Sobre esta base, se indagó la actividad que realizaron las personas con las que mantuvo una relación social. Jóvenes que no ingresaron a las IES tuvieron un acercamiento del $40 \%$ con personas que estudiaban, $50 \%$ trabajaba, y el $10 \%$ no estudiaba ni trabajaba. Las relaciones con personas que no estudian posiblemente generen en los sujetos egresados que no ingresaron a IES hábitos negativos como bajo desempeño académico, mala conducta, deserción escolar, entre otros.

Al tratar de abundar más sobre la categoría, se cuestionó al grupo que ingresó al nivel superior. Se identificó que el $80 \%$ sostuvo relaciones con personas que "estudiaban", el $20 \%$ "trabajaba", sin resultados hacia los que no estudiaban ni trabajan; la evidencia señala relaciones sociales que posiblemente actuaron como determinante para ingresar al nivel superior, al considerar que las personas que están en formación generan hábitos y tendencias educativas. Ello se relaciona con lo expresado por Blanco (2009), quien indica que el ambiente educativo"caracterizado por valores y creencias respecto de la educación, el esfuerzo y el logro, condicionaría los niveles de motivación 
doi: http://dx.doi.org/10.15359/ree.20-3.21

URL: http://www.una.ac.cr/educare

CORREO: educare@una.cr

de los alumnos y, consiguientemente, los aprendizajes" (p. 1034). Sobre este talante, es posible que las relaciones sociales sean uno de los factores que erijan desigualdades educativas.

\section{Categoría: trayectoria académica}

La trayectoria académica del estudiante se sostiene a partir del rendimiento académico obtenido y la aprobación o reprobación de un ciclo escolar. Sobre ello, se expresa que "el destino educativo se construye desde los inicios de la escolarización y forma una ruta que no permite dar marcha atrás. De la misma manera se cargan los logros que las deficiencias. Cada paso, cada etapa, tiene repercusiones en las subsiguientes y pareciera que difícilmente puede romperse el rumbo que se ha trazado" (Guzmán \& Serrano, 2011, p. 45). Sobre lo mencionado, es menester caracterizar la trayectoria académica del egresado, en busca de encontrar factores que posiblemente generen pautas sobre el ingreso o no al nivel superior.

Se revisó la trayectoria académica de estudiantes de primaria, al considerar las dificultades en ese nivel educativo, en el que predomina un problema de cobertura, de calidad y de equidad (Rodríguez, 2008). La reprobación escolar de estudiantes de uno o más ciclos académicos genera impacto desfavorable en el rendimiento académico y en sus aspiraciones futuras (Blanco, 2011). Los resultados para la educación primaria en el grupo que ingresó al nivel superior indican que el $100 \%$ no reprobó un ciclo escolar. Respecto a su promedio académico, un $30 \%$ obtuvo de 8.0 a 8.9 , el $60 \%$ de 9.0 a 9.5 y el $10 \%$ de 9.0 a 10 . Los resultados permiten suponer que las calificaciones sobresalientes señalan a estudiantes con disciplina, responsables y con un conjunto de valores relacionados con el compromiso académico. Además, el no reprobar un ciclo académico permite transitar adecuadamente al siguiente nivel, ya que es probable que se posean los conocimientos necesarios para continuar con la formación educativa.

Mención aparte merece lo expresado por García et al. (1998) que indica: "la reprobación es una decisión muy seria. Siendo algo que puede evitarse si se atiende el rezago escolar progresivo a lo largo de todo el año, resulta una drástica medida que se toma a fin del ciclo y que significa que el niño tiene que repetir todo un curso. Esta decisión frustra y estigmatiza" (p. 331). Sobre lo mencionado, el problema se suscita en jóvenes que "no ingresaron" al nivel superior, al identificar que el $20 \%$ reprobó un ciclo académico y el $80 \%$ logró acreditar los ciclos en la educación primaria. Posiblemente el factor de reprobación fue determinante para obtener un desempeño académico favorable en el siguiente nivel de estudios -secundariae impactó en las aspiraciones académicas de jóvenes que reprobaron un ciclo académico. Su aprovechamiento académico evidencia que el $5 \%$ obtuvo menor o igual a 7.0, el $25 \%$ logró de 7.1 a 7.9 , el $20 \%$ fue de 8.0 a 8.9 , el $40 \%$ de 9.0 a 9.5 y el $10 \%$ de 9.0 a 10 . Es importante mencionar que "el peso de la educación básica en la trayectoria educativa, ya que es en esta etapa en la que se sientan las bases del aprendizaje y que permitirán dar continuidad, facilitar u obstaculizar las etapas posteriores" (Guzmán \& Serrano, 2011, p. 43). 
A partir de lo señalado, posiblemente el bajo rendimiento académico, al considerar el promedio y reprobación, pueden ser factor relevante en la elección de vida profesional. El promedio no garantiza el nivel de conocimientos, pero hace evidente el compromiso que se asume; aunado a ello se señala que "la reprobación aumenta tanto las probabilidades de reprobar nuevamente como las de desertar" (García et al., 1998, p. 331), por lo que el nivel obtenido posiblemente sea factor determinante en los siguientes ciclos académicos.

En la secundaria, el grupo que ingresó al nivel superior en su totalidad no reprobó ningún ciclo escolar (100\%). Su promedio académico se caracterizó porque el $40 \%$ fue de 8.0 a 8.9 , el 10\% de 9.0 a 9.5 y el $50 \%$ de 9.0 a 10. En este nivel se mantiene el desempeño académico del grupo egresado, por lo que posiblemente se afirma que los resultados obtenidos en la primaria sean un factor determinante del éxito académico en los siguientes niveles educativos. En comparación con el grupo que no ingresó al nivel superior, el 100\% no reprobó ningún ciclo escolar y su promedio académico se caracterizó porque el $20 \%$ obtuvo de 7.1 a 7.9 , el $25 \%$ de 8.0 a 8.9 , el $40 \%$ de 9.0 a 9.5 y el $15 \%$ de 9.6 a 10 (ver tabla 4). Los resultados académicos seguramente se atribuyen a la superación y compromiso académico mostrado, sin embargo, se hace evidente que su promedio deja entrever dificultades para que este grupo acceda a estímulos académicos, oportunidades de estudio, así como un reconocimiento institucional por el desempeño. El resultado posiblemente se deba al nivel de escolaridad de los padres y madres de ambos grupos egresados, debido a que su origen académico genera pautas sobre lo señalado por Zagal-Carreño et al. (2006), en cuanto a que "los alumnos con calificaciones sobresalientes tienen que hacer un esfuerzo mayor para obtener mejores calificaciones, independientemente del grado de escolaridad de sus padres" (p. 274).

Tabla 4

Trayectoria académica evidenciada con el porcentaje de reprobación y promedio general en la primaria y secundaria en egresados del C.B.T.a N. 17 que ingresaron yno a IES en Veracruz, México

\begin{tabular}{|c|c|c|c|c|c|c|}
\hline \multicolumn{3}{|c|}{ Dimensiones } & \multicolumn{2}{|c|}{ Sujetos egresados que ingresaron a IES } & \multicolumn{2}{|c|}{ Sujetos egresados que no ingresaron a IES } \\
\hline \multirow{9}{*}{ Indicadores } & Nivel educativo & & Primaria & Secundaria & Primaria & Secundaria \\
\hline & Renrobó un ciclo escolar & No & $100 \%$ & $100 \%$ & $80 \%$ & $100 \%$ \\
\hline & & Sí & $0 \%$ & $0 \%$ & $20 \%$ & $0 \%$ \\
\hline & Promedio general & & & & & \\
\hline & Menor 0 igual a 7.0 & & $0 \%$ & $0 \%$ & $5 \%$ & $0 \%$ \\
\hline & 7.1 a 7.9 & & $0 \%$ & $0 \%$ & $25 \%$ & $20 \%$ \\
\hline & 8.0 a 8.9 & & $30 \%$ & $40 \%$ & $20 \%$ & $25 \%$ \\
\hline & 9.0 a 9.5 & & $60 \%$ & $50 \%$ & $40 \%$ & $40 \%$ \\
\hline & 9.6 a 10 & & $10 \%$ & $10 \%$ & $10 \%$ & $15 \%$ \\
\hline
\end{tabular}

Nota: Elaboración propia. 
doi: http://dx.doi.org/10.15359/ree.20-3.21

URL: http://www.una.ac.cr/educare

CORREO: educare@una.cr

Los resultados exigen la intervención académica por parte del profesorado para mejorar el rendimiento de estudiantes que ingresan al nivel medio superior. Se demuestra un desempeño académico sobresaliente en el grupo que ingresó a IES, por lo que posiblemente cuenten con las competencias necesarias para cursar estudios de forma satisfactoria.

En busca de reforzar la evidencia que argumente el acceso al nivel pregrado de acuerdo con la trayectoria académica, se prosiguió a identificar los resultados en el nivel medio superior de jóvenes que continuaron su formación académica, los cuales demostraron una consistencia favorable, al señalar que el $80 \%$ no reprobó ninguna asignatura, y el $20 \%$ no se ajustó a los estándares de aprobación por parte del maestro o maestra, lo que generó la presentación del examen de recuperación. El índice de reprobación permite afirmar que el grupo presenta tendencias positivas sobre su desempeño académico caracterizado como aceptable, al mostrar que el 50\% obtuvo un rendimiento académico de 9.0 a 10, el $45 \%$ de 8.0 a 8.9 , y el $50 \%$ de 7.1 a 7.9. Las tendencias permiten establecer que no presentan rendimiento académico aceptable. La posible ausencia de hábitos académicos diversificados -así como el compromiso, disciplina y responsabilidad por la formación académica-, pueden estar condicionados por diferentes factores, al asumir que el capital cultural y social impacta en los resultados académicos.

Respecto al grupo que no ingresó al nivel superior, los resultados señalan que el $40 \%$ realizó examen de recuperación y el $60 \%$ aprobó las asignaturas (ver tabla 5). La evidencia permite señalar que "se ha detectado que los alumnos con bajo aprovechamiento generalmente tienen serios problemas familiares, económicos y emocionales" (Zagal-Carreño et al., 2006, p. 263). La reprobación académica se sitúa como un factor problemático en el campo educativo, lo cual hace pensar que posiblemente los factores mencionados son determinantes en el rendimiento académico. Aunado a ello, se sabe que la deficiencia académica, falta de compromiso con la formación, y otros factores propios de las familias con problemas económicos provenientes de zonas rurales, asociados a un bajo nivel de escolaridad, generan mayor posibilidad de abandono educativo, evidenciado principalmente por factores como baja asistencia a la escuela, reprobación y calificaciones irregulares. Por estas razones, es necesario "mejorar la retención en el nivel con ayuda de la figura del tutor, quien propicie que los jóvenes que ingresaron $y$, por tanto, vencieron las barreras, no abandonen el sistema educativo" (Villa, 2014, p. 41). Con base en ello, es posible afirmar que la reprobación de una asignatura hasta su acreditación final se sitúa como un problema determinante para continuar los estudios superiores. Los resultados hacen pensar que la escolaridad de los padres y madres actúa como determinante en la trayectoria académica del alumnado. 
Tabla 5

Trayectoria académica evidenciada con el porcentaje de reprobación y promedio general en el nivel medio superior en sujetos egresados del C.B.T.a N. ${ }^{0} 17$ que ingresaron yno a IES en Veracruz, México

\begin{tabular}{lccc}
\hline \multicolumn{1}{c}{ Dimensiones } & Sujetos egresados que ingresaron a IES & Sujetos egresados que no ingresaron a IES \\
\hline Reprobó un ciclo escolar & No & $80 \%$ & $60 \%$ \\
& Sí & $20 \%$ & $40 \%$ \\
\hline Promedio general obtenido & & \\
\hline Menor o igual a 7.0 & $0 \%$ & $0 \%$ \\
7.1 a 7.9 & $5 \%$ & $25 \%$ \\
8.0 a 8.9 & $45 \%$ & $25 \%$ \\
9.0 a 9.5 & $35 \%$ & $45 \%$ \\
9.6 a 10 & $15 \%$ & $5 \%$ \\
\hline
\end{tabular}

Nota: Elaboración propia.

Basándose en esta evidencia, se identificó el promedio general obtenido en el bachillerato, lo que mostró que el 50\% obtuvo un promedio de 9.0 a 10, así como de 7.1 a 8.9 para el resto de los sujetos egresados. Los resultados permiten indicar una trayectoria académica con índices de reprobación y bajo aprovechamiento académico, lo cual sitúa al estudiantado con menor posibilidad de ingresar a estudios del nivel superior. Los resultados permiten afirmar que posiblemente el hogar del que proviene el sujeto egresado sea otro factor determinante en el ingreso académico, al señalar lo expresado por Blanco (2014) al respecto: "la estructura del hogar se asocia significativamente con la finalización de la EMS. Específicamente, cualquier tipo de hogar distinto del modelo nuclear (ambos padres, sin otros familiares) reduce los momios de finalizar" (p. 266), sujeto al rendimiento académico obtenido.

\section{Conclusiones}

El estudio, por su carácter exploratorio-descriptivo, permite acercarse a factores que posiblemente generan pautas sobre las causas que afectan el proceso de transición en grupos egresados con diferentes orígenes sociales, culturales y académicos que aspiran ingresar al nivel superior, caracterizado por una persistente desigualdad educativa.

Se hace evidente que el género femenino favoreció el ingreso al nivel superior posiblemente por su capacidad académica -habilidades y destrezas-y humana. En comparación con los hombres, quienes no continuaron su formación al señalar que posiblemente no están 
doi: http://dx.doi.org/10.15359/ree.20-3.21

URL: http://www.una.ac.cr/educare

CORREO: educare@una.cr

preparados ni académica ni humanamente para enfrentar el proceso de transición educativa. Aunado a ello, los grupos egresados que habitaron en localidades rurales están expuestos a menores oportunidades de estudio y problemas relacionados con la marginación y pobreza, las cuales actúan como determinantes en el nivel de escolaridad.

Sobre este talante, jóvenes que provienen de padres y madres con bajo nivel de escolaridad y sin formación académica tienen menos probabilidad de continuar sus estudios. Con ello se indica que descender de progenitores que ingresaron a nivel educativo, pero desertaron en el proceso, se yergue como un posible factor que promueve en los hijos e hijas la superación académica, con lo que se evita sostener la premisa ya señalada sobre el origen, el cual nunca es destino.

En el abordaje sobre el capital social se identificó que los hogares disfuncionales, ausencia de madre o padre, posiblemente sean un factor que genera desigualdad en el ingreso al nivel superior, debido a que la mayoría de quienes no continuaron su ingreso a IES presentaron esta cualidad. Se señala que la mayor presencia de hermanos o hermanas es una condicionante en el grupo que no continúo su formación académica, lo que es posible la presencia de problemas económicos y falta de atención académica.

Las relaciones sociales del grupo que no ingresó a IES se comportan como factor situado fuera de la trasmisión de conductas hacia la superación académica, debido a que están en estrecho contacto con personas que no estudian, pero tampoco trabajan. Con base en ello, es posible sostener que el tipo de relación social influye sobre el ingreso al nivel superior, lo que deja entrever una serie de dificultades en jóvenes que provienen de zonas rurales, en donde el nivel de escolaridad es inferior que en las zonas urbanas y al no tener otra opción de relación se generan redes con características similares.

La trayectoria académica de los sujetos egresados que ingresaron al nivel superior se caracterizó por un promedio aceptable y bajo índice de reprobación; evidencia que señala un compromiso en su formación académica, con la capacidad para continuar su formación superior. Sin embargo, el problema se hace evidente en jóvenes que no ingresaron a las IES, debido a que su formación académica está caracterizada por la reprobación de un ciclo escolar y el bajo promedio académico, por lo que posiblemente son factores que trazaron su destino.

Los resultados dejan entrever un problema en el acceso al nivel superior, caracterizado por una persistente desigualdad educativa debido al origen de la juventud, por lo que se recomienda fortalecer el programa de tutorías atendiendo las problemáticas familiares y académicas del alumnado; desarrollar estrategias didácticas en el proceso de aprendizaje en español y matemáticas. Finalmente, es necesario que las instituciones del nivel superior consideren en su alumnado una "formación humana", centrada en su actividad fuera del ámbito educativo, que oriente el destino académico. 


\section{Referencias}

Álvarez-Gayou, J. L. (2003). Cómo hacer investigación cualitativa. Fundamentos y metodología. México: Paidós Mexicana.

Amato, P. R. (Mayo, 1987). Family processes in one-parent, stepparent, and intact families: The child's point of view [Procesos familiares en uno de los padres, padrastros y familias intactas: Punto de vista de los niños]. Journal of Marriage and Family, 49(2), 327-337. doi: http://dx.doi.org/10.2307/352303

Astone, N. M. , \& McLanahan, S. (Junio, 1991). Family structure, parental practices and high school completion [Estructura familiar, las prácticas parentales y terminación de la High School secundaria]. American Sociological Review, 56(3), 309-320. doi: http://dx.doi. org/10.2307/2096106

Blanco, E. (Octubre, diciembre, 2009). La desigualdad de resultados educativos. Aportes a la teoría desde la investigación sobre eficacia escolar. Revista Mexicana de Investigación Educativa, 14(43), 1019-1049. Recuperado de http://www.scielo.org.mx/pdf/rmie/v14n43/ v14n43a3.pdf

Blanco, E. (2011). Los límites de la escuela. Educación, desigualdad y aprendizaje en México. México: El Colegio de México, Centro de Estudios Sociológicos. Recuperado de http://www.ses. unam.mx/curso2013/pdf/BlancoEmilio.pdf

Blanco, E. (Abril-junio, 2014). La desigualdad social en el nivel medio superior de educación de la Ciudad de México. Papeles de población, 20(80), 249-280. Recuperado de http://www. redalyc.org/articulo.oa?id=11231067009

Blanco, R., \& Cusato, S. (s. f.). Desigualdades educativas en América Latina: Todos somos responsables. Documento de trabajo. Recuperado de http://www.red-ler.org/ desigualdades educativas america latina.pdf

Bourdieu, P. (2001). Poder, derecho y clases sociales (2a ed.). Bilbao: Desclée de Brouwer.

Centro de Bachillerato Tecnológico agropecuario N. 17 (C.B.T.a N.' 17). (2016). Recuperado de http://cbta17.es.tl/C-.-B-.-T-.-a-.htm

Colorado, A. (2009). El capital cultural y otros tipos de capital en la definición de las trayectorias escolares universitarias (Área 16: sujetos de la educación). En X Congreso Nacional de Investigación Educativa (pp. 1-21). Veracruz, México: Consejo Mexicano de Investigación Educativa. Recuperado de http://www.comie.org.mx/congreso/memoriaelectronica/v10/ pdf/area tematica 16/ponencias/1732-F.pdf 
doi: http://dx.doi.org/10.15359/ree.20-3.21

URL: http://www.una.ac.cr/educare

CORREO: educare@una.cr

Declaración Universal de Derechos Humanos (1948). Recuperado de http://www.un.org/es/ documents/udhr/index print.shtml

Fernández, T. (Septiembre, 2002). Determinantes sociales e institucionales de la desigualdad educativa en sexto año de educación primaria de Argentina y Uruguay, 1999. Una aproximación mediante un modelo de regresión logística. Revista Mexicana de Investigación Educativa, 7(16), 501-536. Recuperado de http://www.redalyc.org/articulo. oa?id=14001605

García, H., Bracho, T., Ibarrola, M., Rodríguez, R., \& Schmelkes, S. (Julio-diciembre, 1998). Educación y desigualdad social. Revista Mexicana de Investigación Educativa, 3(6), 317-345. Recuperado de http://www.comie.org.mx/v1/revista/portal. php?idm $=$ es \&sec $=$ SC01\&sub $=$ SBA\&criterio $=$ N006

Gobierno de los Estados Unidos Mexicanos. (2014). 1er Informe de Gobierno 2012-2013. México: Autor. Recuperado de http://www.presidencia.gob.mx/primerinforme/

Guzmán, C., \& Serrano, O. V. (Enero-marzo, 2011). Las puertas del ingreso a la educación superior: El caso del concurso de selección a la licenciatura de la UNAM. Revista de la educación superior, 40(157), 31-53. Recuperado de http://www.redalyc.org/articulo. oa?id=60420223002

Latapí, P. (Septiembre-diciembre, 2002). [Reseña de libro Distintas escuelas, diferentes oportunidades.Los retos paralaigualdad deoportunidades en Latinoamérica, porF.Reimers (Coord.)]. Revista Mexicana de Investigación Educativa, 7(16), 665-669. Recuperado de http:// www.comie.org.mx/v1/revista/portal.php?idm=es\&sec=SC01\&sub=SBA\&criterio=N016

Marchesi, Á. (Mayo-agosto, 2000). Un sistema de indicadores de desigualdad educativa. Revista Iberoamericana de Educación, 23, 135-163. Recuperado de http://rieoei.org/rie23.htm

Martínez-Salgado, C. (2012). El muestreo en investigación cualitativa. Principios básicos y algunas controversias. Ciencia \& Saúde Coletiva, 17(3), 613-619. doi: http://dx.doi.org/10.1590/ $\underline{\mathrm{S} 1413-81232012000300006}$

Muñoz-Izquierdo,C.(1996). Origen yconsecuencias delas desigualdades educativas. Investigaciones realizadas en América Latina sobre el problema. México: Fondo de Cultura Económica.

Ortiz, L. (2014). Formas y extensiones de la desigualdad escolar. Acerca del sistema educativo paraguayo. Revista de Internacional de Investigación en Ciencias Sociales, 10(1), 45-59. Recuperado de http://revistacientifica.uaa.edu.py/index.php/riics/article/view/197

Ramírez, J., \& Hernández, E. (2012). ¿Tenía razón Coleman? Acerca de la relación entre capital social y logro educativo. Sinéctica. Revista Electrónica de Educación, 39, 1-14. Recuperado de https://sinectica.iteso.mx/index.php/SINECTICA/article/view/79/71 
Rodríguez, C. R. (2008, otoño). Equidad de la educación en México. Propuesta de un sistema de indicadores. Revista Perspectivas Sociales, 10(2), 55-79. Recuperado de http://www.uaeh. edu.mx/investigacion/icshu/LI EstuSociales/Carlos Solera/Equidad.pdf

Rodríguez, R. (1999). Género y políticas de educación superior en México. Revista de Estudios de Género. La Ventana, 10, 124-159. Recuperado de http://www.redalyc.org/articulo. oa?id=88411129006

Rosero, A. R. (Enero-junio, 2012). Percepciones y prácticas de gestión de directivos y docentes en instituciones educativas del municipio de pasto. Revista Unimar, 59, 41-54. Recuperado de http://www.umariana.edu.co/ojs-editorial/index.php/unimar/article/view/227/200

Sandefur, G. D., Mclanahan, S., \& Wojtkiewicz, R. (1992). The effects of parental marital status during adolescence on high school graduation [Los efectos del estado civil de los padres durante la adolescencia en la graduación de secundaria]. Social Forces, 71(1), 103-121. doi: http://dx.doi.org/10.2307/2579968

Secretaría de Educación Pública (SEP). (2001). Programa Nacional de Educación 2001-2006. Por una educación de buena calidad para todos. Un enfoque educativo para el siglo XXI. Recuperado de: http://www.oei.es/quipu/mexico/Plan educ 2001 2006.pdf

Secretaría de Educación Pública (SEP). (2014a). Evaluación nacional del logro académico en centros escolares (ENLACE). Educación media superior. México: Autor.

Secretaría de Educación Pública (SEP). (2014b). Sistema educativo de los Estados Unidos Mexicanos. Principales cifras. Ciclo escolar 2013-2014. México: Autor. Recuperado de: http://www. planeacion.sep.gob.mx/Doc/estadistica e indicadores/principales cifras/principales cifras 2013 2014.pdf

Solís, P. (2014). Mayor matrícula universitaria, ¿mayor equidad social? Educación futura. Recuperado en: http://www.educacionfutura.org/mayor-matricula-universitaria-mayorequidad-social/

Sousa, R., Lopes, A., \& Ferreira, E. (Octubre-diciembre, 2013). La transición y el proceso de adaptación a la educación superior: Un estudio con estudiantes de una escuela de enfermería y de una escuela de educación. REDU. Revista de Docencia Universitaria, 11(3), 403-422. Recuperado de http://www.polipapers.upv.es/index.php/REDU/article/ view/5535

Villa, L. (Enero-abril, 2014). Educación media superior, jóvenes y desigualdad de oportunidades. Innovación Educativa, 14(64), 33-45. Recuperado de http://www.scielo.org.mx/pdf/ie/ v14n64/v14n64a4.pdf 
doi: http://dx.doi.org/10.15359/ree.20-3.21

URL: http://www.una.ac.cr/educare

CORREO: educare@una.cr

Zagal-Carreño, B., Cruz-Lozano, M.A., Ramírez-Valverde, B., Herrera-Cabrera, B. E., Macías-López, A., \& Martínez-Saldaña, T. (2006). Características socioeconómicas, rendimiento escolar y expectativas de estudios superiores de los estudiantes de los bachilleratos agropecuarios: Estudio en la región norte del estado de Guerrero, México. Revista Latinoamericana de Estudios Educativos, 36(3-4), 261-281. Recuperado de http://www.redalyc.org/ pdf/270/27036411.pdf

\section{Cómo citar este artículo en APA:}

Pérez-Santiago, F. y Villarruel-Fuentes, M. (Setiembre-diciembre, 2016). Desigualdad en el acceso educativo en México: Un estudio con sujetos egresados de un bachillerato tecnológico de alto desempeño. Revista Electrónica Educare, 20(3), 1-22. doi: http://dx.doi.org/10.15359/ree.20-3.21

Nota: Para citar este artículo en otros sistemas puede consultar el hipervínculo "Como citar el artículo" en la barra derecha de nuestro sitio web: http://www.revistas.una.ac.cr/index.php/EDUCARE/index 